\title{
Employee's Job Satisfaction and Supervisors Performance at Debre Berhan University
}

\author{
Getahun Mulugeta \\ Department of Statistics, Debre Berhan University, Debre Berhan, Ethiopia
}

Email address:

gech.marr@gmail.com

To cite this article:

Getahun Mulugeta. Employee's Job Satisfaction and Supervisors Performance at Debre Berhan University. American Journal of Theoretical and Applied Statistics. Vol. 7, No. 2, 2018, pp. 85-91. doi: 10.11648/j.ajtas.20180702.15

Received: March 5, 2018; Accepted: March 14, 2018; Published: March 22, 2018

\begin{abstract}
In order to ensure the achievement of organization's goals, it should create an atmosphere of commitment and cooperation for its employees through policies that facilitate employee satisfaction. The main objective of the study is identifying factors affecting employee's job satisfaction and supervisor performance at Debre Berhan University. In order to meet the objective of the study a sample of 272 employees have taken. And consecutive statistical methods have been used. Both descriptive and inferential group of statistical tools have been applied. The descriptive result of the study reveals that about $63.2 \%$ of the sampled employees have unsatisfied and the rest $36.8 \%$ of them have satisfied with the working condition of the university. From logistic regression analysis of job satisfaction it is evident that the way of promotion, encouragement of research work, accessibility of office, merit based job allocation, recognition for contributions, responding the need of home and facility of working materials have significant effect on employees job satisfaction at $5 \%$ level of significant. Multiple linear regression also shows that handles employees complaints, does not allow special privilege, availability of supervisor for staffs, being respectful, good leading skill, trust on clerk, and sense of responsibility have significant effect on the supervisor performance at $5 \%$ level of significance. Finally chi-square test of association of overall job satisfaction and overall supervisor performance shows that there is a strong association between job satisfaction and performance of immediate supervisors. from consecutive result of the study it is recommended that; the management of the university should improve the way of promotion for staffs based on the legislation of the university, there should be motivated encouragement and recognition for researchers so that scientific environment can be created in the compound, the university should also work hard to satisfy the need of staffs for home and the allocation of supervisors in different hierarchy should be merit based.
\end{abstract}

Keywords: Job Satisfaction, Supervisor Performance, Logistic Regression, Multiple Linear Regression, Debre Berhan University

\section{Introduction}

\subsection{Background of the Study}

An Organization is a social built place where human resource plays a very significant role in its effectiveness and efficiency. Managing these resources is an important aspect of organizational processes. This emanated from the recognition that the human resources of an organization and the organization itself are synonymous [4]. A well-managed business organization normally considers the average employees as the primary source of productivity gains. These organizations consider employees rather than capital as the core foundation of the business and contributors to firm development. To ensure the achievement of firm goals, the organization creates an atmosphere of commitment and cooperation for its employees through policies that facilitate employee satisfaction. Satisfaction of human resource finds close links to highly motivated employees. Motivated employees then develop loyalty or commitment to the firm resulting to greater productivity and lower turnover rates [3].

Effective leaders (manager) and employees are those who give great help to any organization to achieve its objectives and goals. Their personal effort and commitment with organization is that which help organization to succeed [10]. Many observations and many academic documents and 
circles agreed that leadership have great impact on job satisfaction of any singles employee [5]. Organizations always try to earn more profit. Organization's profit is related to productivity of firms. And productivity of any firm is increased by its employee. So for satisfaction of employs any organization takes many steps. In these steps one step is that organization provides him a best manager or supervisor who trains them in their work for giving best output to organization because coordination with manager and employee is very important to full fill any task at given time [8]. So for making strong communications between employee and their supervisor organization asked to manager to make strong relationship with his all employee so they easily and happily work with that supervisor and loyal to their organization [1]. Manager is only those keys which clearly define any organization goals and aims of working and guide the best way which fulfill the organization goals and aims [6]. So the paper is motivated to realize the existing job satisfaction of employees and supervisor performance at Debre Berhan University.

\subsection{Statements of the Problem}

Job satisfaction is one prototype of organizational commitment and turnover intention which suggest that the high level of job satisfaction leads to higher commitment and lower turnover intention [9]. Lack of employees' continuity involves high costs in the induction and training of new staff; organizational productivity is one of the challenges that arise as a result of turnover [7].

The point that initiates us to apply our effort on such a topic is the idea raised from the employees of the university on the 2014 training of government policy and strategy on sector agenda both in group discussion and the so-called "hail medrek". From the conference there was a clear indication of employees are not comfortable with their jobs and they have a full of complains with their supervisor. This was our motive of conducting this research. But immediate changes have been recorded. Like; payment of overload becomes semester wise, transportation service has given for staffs, internet access has improved and the like. Due to such improvement the researcher feels that the title of the paper may not be consistent with the core problem of the university. Because of this reason we have hesitated to finalize the study and the study time has been extended up to now. Based on the direction given by research directorate director, we have planned to finalize the study by addressing other unimproved service of the university. Accordingly the study has been designed to address the following research questions:

What the real existing employees' job satisfaction in DBU looks like?

What are the major factors that affect job satisfaction of employees?

What are the major determinants of supervisor performance?

Is there any association between job satisfaction and supervisor performance?
The main objective of the study is to identify factors affecting employee's job satisfaction and supervisor performance at Debre Berhan University

Specifically the paper aimed to:

To assess the level of satisfaction of employees in the university;

To identify factors affecting employee's job satisfaction in DBU

To examine the determinants of supervisor performance in the study area

To analyze whether there is association between job satisfaction and supervisor performance;

To provide information for the board of the university at large;

\section{Method}

\subsection{Data Source}

Primary source of data was used. Once we have obtained the total number of employees (both academic and administrative staffs) in the university from personnel department, we have collected the information from selected staffs through standard, structured and pre tested questionnaire.

\subsection{Sampling Design}

The target population for this study is the total number of employees in the university, from guard to president office except students and contract employees. Since job satisfaction varies through academic and administrative staffs stratified random sampling was used in order to capture the variability due to staff groups. Therefore there are two strata the first one is academic staffs the second one is administrative staffs. Staffs were selected from each stratum proportionally by using simple random sampling and all the available department staffs of randomly selected employee were considered until the saturation of sample size. So that Standard, structured and pre tested questionnaire was distributed in both academic and administrative staffs. The data for the analysis was generated from the individual employee response to the items on the survey questionnaire. The questionnaire has two parts; questions about employee's job satisfaction and questions about supervisor performance. The response on any item ranged from 0 through 4, indicating very satisfactory to very unsatisfactory, respectively. A dichotomous index was created to each item by collapsing the response scale to two categories: $\{0,1\}$, to be interpreted as a favorable response, and $\{2,3,4\}$, representing an unfavorable response. The data was collected from randomly selected staffs of the university. The data for second part of the study (supervisor performance) was obtained by taking proportion of favorable responses in the department, which is continuous. For the first part (employee's job satisfaction) we have used the already dichotomized responses, which is categorical. 


\subsection{Sample Size Determination}

Determining the sample size for a study is a crucial component of study design. The goal is to include sufficient numbers of subjects so that statistically significant results can be detected. In order to have an optimum sample size, there are a number of issues/points one has to take into account. Some of the issues are: objective of the research, design of the research, cost constraint, plan for statistical analysis, degree of precision required for generalization, degree of confidence with which to conclude etc. As mentioned in sampling design, sample size determination technique used in this study will stratified random sampling techniques. Accordingly, sample size determination formula for categorical data analysis is used. The minimum sample size (from $\mathrm{N}_{\mathrm{e}}=$ 1351 and $N_{d}=68$ ) required is given by:

$$
\mathrm{n}_{\mathrm{o}}=\frac{\mathrm{z}_{\alpha / 2}{ }^{2} \boldsymbol{P} \boldsymbol{Q}}{\mathrm{E}^{2}}
$$

Where $\mathrm{P}$ is proportion of favorable response of employees, since there is no evidence about population proportion pilot survey has been conducted. 30 staffs have been asked on their level of satisfaction for the purpose of pilot. 9 of them have favorable response and 21 of them have unfavorable response. So the proportion of favorable response $(\mathrm{P}=0.3)$ and unfavorable response $(\mathrm{Q}=1-\mathrm{P}=0.7)$. The margin of error E, which is usually set by the investigator and its specification must be small to have a good precision, is 0.03 . Degree of confidence $Z \alpha / 2$ is the upper points of standard normal distribution with $\alpha=0.05$ level of significance, which is $\mathrm{Z} \alpha / 2=1.96$. With these given information, the initial sample size is 322 , which is greater than $5 \%$ of $\mathrm{Ne}$, therefore we can extend the above formula to:

$$
\mathrm{n}=\frac{\boldsymbol{n}_{\boldsymbol{o}}}{1+\frac{\boldsymbol{n}_{\boldsymbol{o}}}{\boldsymbol{N}_{\boldsymbol{d}}}}
$$

Its value becomes 259 with $5 \%$ nonresponse rate the final sample size of the survey is 272 . Therefore 272 staffs were taken from the total of 1351 employees of the university (both academic and administrative staffs). The final sample size $(n=272)$ is proportionally allocated for both academic and administrative staffs through proportional allocation, nh is sample size for strata $h$, here we have two strata (academic and administrative), is given by:

$n_{h}=n * N_{h} / N_{e}$, where $N_{h}$ is population size of the stratum $h$, $\mathrm{N}$ is total population size, $\mathrm{h}$ is index of strata $=1,2$, and $\mathrm{n}$ is total sample size of the survey.

Substituting the value of parameters for each stratum gives:

$$
\begin{aligned}
& \mathrm{n}_{1}=\mathrm{n} * \mathrm{~N}_{1} / \mathrm{N}_{\mathrm{e}}=272 * 797 / 1351=160 \\
& \mathrm{n}_{2}=\mathrm{n} * \mathrm{~N}_{2} / \mathrm{N}_{\mathrm{e}}=272 * 554 / 1351=112
\end{aligned}
$$

Therefore 160 academic and 112 administrative staffs have taken as the sampling units of the study.

\subsection{Variables Considered in the Study}

\subsubsection{Dependent Variables}

There are two dependent variables in the study. The first one is employees' job satisfaction (Y1), which is a categorical variable dichotomy as satisfied and dissatisfied. The second one is supervisor performance (Y2), it is a proportion of favorable response, which is continues variable can be analyze through multiple linear regression. The corresponding independent variables are listed below, which are also dichotomies in to two categories.

\subsubsection{Independent Variables}

Predictors of Y1

Reasonable workload

Facility of working materials

Promotion

Reward (payment)

Nature of work

Relationship with co-workers

Academic freedom

Encouragement of research work

Responding the question of staffs with respect to home

Recognition and rewards for contributions

Access of office for staffs

Predictor of Y2

Handles employee complaints

Does not allow special privileges

Opportunity to learn new things

Raises based on performance

Rate of advancing to better jobs

Available for customers

Respectful

Work with plan

Responsible

Leading skill

Can be role model for others

\subsection{Method of Analysis}

In addition to simple descriptive statistics three inferential statistical models were used; the first one is binary logistic regression for employees' job satisfaction, multiple linear regression for performance of supervisors and chi square test of association to examine the association of job satisfaction and supervisor performance.

\subsubsection{Logistic Regression}

Logistic regression analysis extends the techniques of multiple regression analysis to research situations in which the outcome variable is categorical. When we assume that $\mathrm{Y}$ is dichotomous, taking on values of 1 (that is, positive outcome, or success) and 0 (that is, negative outcome, or failure). Then the conditional probability of job satisfaction given the $\mathrm{X}$ set of predictor variables is denoted by Prob $\left(\mathrm{Y}_{\mathrm{i}}\right.$ $=1 \mid \mathrm{X})=\mathrm{P}_{\mathrm{i}}$. The expression $\mathrm{P}_{\mathrm{i}}$ has the form: 


$$
P_{i}=\frac{e^{\left(\beta_{0}+\beta_{1} x_{1 i}+\beta_{2} x_{2 i}+\cdots+\beta_{r} x_{r i}\right)}}{1+e^{\left(\beta_{0}+\beta_{1} x_{1 i}+\beta_{2} x_{2 i}+\cdots+\beta_{r} x_{r i}\right)}}=\frac{e^{x^{\prime} \beta}}{1+e^{x^{\prime} \beta}}
$$

$P_{i}=$ the probability of job satisfaction of respondent $i$ being satisfied

$\mathrm{Y}_{\mathrm{i}}=$ the observed job satisfaction of employee $\mathrm{i}$

$\beta$ is a vector of unknown coefficients. Maximum likelihood estimation method is appropriate for estimating the logistic model parameters due to this less restrictive nature of the underlying assumptions (Hosmer - Lemeshow, 1989). Hence, in this study the maximum likelihood estimation technique was applied to estimate parameters of the model. Consider the logistic model $\mathrm{P}_{\mathrm{i}}=\frac{\mathrm{e}^{\mathrm{x}^{\prime} \beta}}{1+\mathrm{e}^{\mathrm{X}^{\prime} \beta}}$, since observed values of $\mathrm{Y}$ say, $\mathrm{y}_{\mathrm{i}}$ 's $(\mathrm{i}=1,2,3 \ldots, \mathrm{n})$ are independently distributed as binomial with parameter $\mathrm{P}_{\mathrm{i}}$, the maximum likelihood function of $\mathrm{Y}$ is given by:

$$
L(\beta \mid Y)=\prod_{i=1}^{n} P\left(y_{i} \mid X_{i 1}, X_{i 2}, \ldots, X_{i m}\right)=\prod_{i=1}^{n}\left[\frac{e^{X^{\prime} \beta}}{1+e^{X^{\prime} \beta}}\right]^{y_{i}}\left[\frac{1}{1+e^{X^{\prime} \beta}}\right]^{(1-y}
$$

Where, $\beta^{\prime}=\left(\beta_{1}, \beta_{2}, \quad, \beta_{\mathrm{r}}\right)$

The objective of stating likelihood function is to get an estimator $\hat{\beta}=\left(\hat{\beta}_{0}, \hat{\beta}, \ldots, \hat{\beta_{\mathrm{r}}}\right)$ of $\beta$ which maximizes the likelihood function expressed in equation (2.3).

Assumptions of logistic regression:

The logistic regression coefficients must be coded meaningfully by giving the codes 0 for the dependent class of lower interest and 1 for the dependent class of greatest interest.

The dependent variable must be categorical.

The independent variables need not be interval, nor normally distributed, nor linearly related, nor of equal variance within each group.

Linearity in the logit regression equation should have a linear relationship with the logit form of the dependent variable.

All relevant variables must be included and all irrelevant variables must be excluded.

Absence of Multicolliniarity. As with multiple regressions, multi co linearity is a potential source of confusing or misleading results and needs to be assessed. Multicolliniarity occurs when there are high inter correlations among some set of predictor variables.

The sample size must be large in order to make the Logistic regression accurate.

Error terms are assumed to be independent (independent sampling).

\subsubsection{Multiple Linear Regression}

It shows the linear relationship between one continuous response variable and two or more predictor variables. The data consist of $\mathrm{n}$ observations on a dependent or response variable $\mathrm{Y}$ and $\mathrm{p}$ predictor or explanatory variables, $\mathrm{X} 1$, $\mathrm{X} 2, \ldots, \mathrm{Xp}$. The relationship between $\mathrm{Y}$ and $\mathrm{X}_{1}, \mathrm{X}_{2}, \ldots, \mathrm{X}_{\mathrm{p}}$, is formulated as a linear model.

$$
\mathrm{Y}=\beta \mathrm{o}+\beta_{1} \mathrm{X}_{1}+\beta_{2} \mathrm{X}_{2}+---+\beta_{\mathrm{p}} \mathrm{X}_{\mathrm{p}}+\varepsilon
$$

Where $\mathrm{Y}$ is the proportion of favorable response in overall supervisor performance, Xi's are the average likert scale value of different predictors of supervisor performance at each department of selected staff, $\beta \mathrm{o}, \beta 1, \beta 2, \ldots, \beta \mathrm{p}$, are constants referred to as the regression coefficients and $\varepsilon$ is a random disturbance or error. It is assumed that for any set of fixed values of $X 1, X 2, \ldots, X p$, that fall within the range of the data, the linear equation (3.5) provides an acceptable approximation of the true relationship between $\mathrm{Y}$ and the X's ( $\mathrm{Y}$ is approximately a linear function of the $\mathrm{X}$ 's, and $\varepsilon$ measures the discrepancy in that approximation). In particular, $\varepsilon$ contains no systematic information for determining $\mathrm{Y}$ that is not already captured by the X's.

Assumptions of Multiple Linear Regressions

There are many assumptions to consider but we will focus on the major ones that are easily tested with SPSS. The assumptions for multiple regression includes the following:

The response variable must be continuous.

The relationship between each of the predictor variables and the dependent variable must be linear with respect to the parameters.

The error terms or residuals are normally distributed with constant variance and uncorrelated with the predictors.

Absence of Multicolliniarity, which can lead to misleading and/or inaccurate results. Multicolliniarity (or Collinearity) occurs when there are high inter correlations among some set of the predictor variables. In other words, Multicolliniarity happens when two or more predictors contain much of the same information.

\subsubsection{Test of Association (Chi-square)}

The test that mainly used to test association or inter correlation of two categorical variables is called chi-square analysis. Here chi square test was used to test the association of employee's job satisfaction with their supervisor performance.

Hypothesis testing

Step1. Ho: the two attribute (characters) of elements are independent. Hi: the two attributes (characters) are associated to each other.

Step2. Level of significance

Step3. Test statistics

$$
\chi_{c a l}^{2}=\frac{\sum\left(\boldsymbol{o}_{i j}-E_{i j}\right)^{2}}{E_{i j}}
$$

Where, $\boldsymbol{O}_{i j}-$ Observed frequency

$\boldsymbol{E}_{i j}-$ Expected frequency

Step4. The critical value

$\boldsymbol{\chi}_{\text {cal }}^{2}=\boldsymbol{\chi}_{\boldsymbol{\alpha}}^{2}(\boldsymbol{r}-1)(\boldsymbol{c}-1)$, degree of freedom, $\mathrm{r}=$ Number of raw andc $=$ Number of column

Step5. Decision rule: reject Ho: if

$$
\chi_{c a l}^{2}>\chi_{\text {tab }}^{2}=\chi_{\alpha}^{2}(r-1)(c-1)
$$


Or reject Ho if $\mathrm{p}$-value $<(\boldsymbol{\alpha})$ level of significance

In this study we used $\boldsymbol{\alpha}=0.05$ as a level of significance

Assumption of chi- square

Each and every individual or objects are independents of each other.

Each member quantities are assigned for one and only one cell in the table.

The variables under the study must be categorical.

If the sample data is displayed on continuous table, the expected frequency counts for each cells of table is five.

The population is ten times as large as its respective sample.

\section{Result and Discussion}

This chapter contains a numerical description and statistical analysis of the study data. The main objective of the study is to identify factors affecting employee's job satisfaction and supervisor performance at Debre Berhan University. In order to meet the objective of the study both descriptive and inferential statistical analysis were employed. SPSS v.20 was used for analysis purpose. Descriptive statistics has used to assess the existing situation of job satisfaction of employees in Debre Berhan University, whereas, inferential statistics like; logistic regression, multiple linear regression and chi-square test of association have used to investigate the relationship between variables under the study.

Descriptive result of the study shows that about $63.2 \%$ of the

total sampled respondents have unsatisfied and the remaining $36.8 \%$ have satisfied with the working condition of the university.

\subsection{Logistic Regression Analysis of Job Satisfaction}

The result shows that payment for overload, the way of promotion, encouragement of research, accessibility of office, merit based job allocation, recognition for contributions, responding the need of home and facility of working materials have significant effect on employees job satisfaction at $5 \%$ level of significant.

From descriptive and inferential logistic regression result of the study it is evident that promotion, encouragement of research, accessibility of office, recognition for contribution and responding the need of home are source of dissatisfaction of employees of the university. This result supports the result of Tam [7]. Separate analysis of each variables shows that, employees who have satisfied on the way of promotion of staffs were 7.7 times more satisfied on their overall satisfaction than that of employees who have not satisfied on promotion.

Similarly staffs, who have satisfied on the encouragement of research work were 8.9 times more satisfied on their working condition than that of staffs who have not satisfied on encouragement of research work. Referring response to the need of home shows that employees who have satisfied on the response to the need for home were 8.8 times more satisfied on their working condition than that of employees who have not satisfied on the response to the need of home. The detailed separate analysis has given in the following table which is indicated on the last column (Exp (B)).

Table 1. Logistic regression result of job satisfaction.

\begin{tabular}{|c|c|c|c|c|c|}
\hline Variables & B & S.E. & df & Sig. & $\operatorname{Exp}(B)$ \\
\hline reasonable work load & 1.243 & 0.752 & 1 & .098 & 3.466 \\
\hline payment for overload & 1.565 & 0.808 & 1 & .007 & 4.783 \\
\hline social committees & 1.025 & 1.002 & 1 & .103 & 2.788 \\
\hline the way of promotion & 2.041 & 0.245 & 1 & .005 & 7.699 \\
\hline encouragement of research & 2.181 & 0.337 & 1 & .019 & 8.856 \\
\hline accessibility of office & 2.229 & 0.322 & 1 & .008 & 9.290 \\
\hline merit based job allocation & 1.073 & 1.123 & 1 & .035 & 2.925 \\
\hline recognition for contributions & 2.188 & 0.255 & 1 & .001 & 8.918 \\
\hline responding the need of home & 2.175 & 1.034 & 1 & .002 & 8.803 \\
\hline job security & 0.673 & 0.998 & 1 & .056 & 1.961 \\
\hline facility of working materials & 1.007 & 0.624 & 1 & .035 & 2.738 \\
\hline refreshing activity & 1.946 & 1.214 & 1 & .078 & 7.001 \\
\hline absence of job interference & 0.210 & 1.411 & 1 & .069 & 1.234 \\
\hline
\end{tabular}

\subsection{Multiple Linear Regression of Supervisor Performance}

Individual parametric test or what do we mean by t-test shows the effect of each predictor variables to the response variable. From the result below it is evident that handles employees complaints, does not allow special privilege, available for customers, respectful, good leading skill, trust on clerk and sense of responsibility have significant effect on the supervisor performance at 5\% level of significance. that means in order to say a supervisor has good performance he/she must handles employees complaints, does not allow special privilege, available for customers, be respectful, has good leading skill, should has trust on clerks and sense of responsibility. The detailed output on the effect of individual predictor variables to the overall performance of supervisor is given as follow. 
Table 2. Multiple linear regression of supervisor performance.

\begin{tabular}{|c|c|c|c|c|c|}
\hline \multirow{2}{*}{ Variables } & \multicolumn{2}{|c|}{ Unstandardized Coefficients } & \multirow{2}{*}{$\begin{array}{l}\text { Standardized Coefficients } \\
\text { Beta }\end{array}$} & \multirow{2}{*}{$\mathbf{t}$} & \multirow{2}{*}{ Sig. } \\
\hline & B & Std. Error & & & \\
\hline (Constant) & .199 & .025 & .267 & 7.935 & .000 \\
\hline handles complaints & .334 & .056 & .359 & 5.913 & .005 \\
\hline does not allow special privilege & .723 & .079 & .695 & 9.127 & .015 \\
\hline raises based on performance & .054 & .039 & .053 & 1.380 & .175 \\
\hline available for staffs & .723 & .079 & .695 & 9.127 & .013 \\
\hline respectful & .148 & .070 & .158 & 2.106 & .037 \\
\hline work with plan & .135 & .035 & .154 & 3.829 & .071 \\
\hline good leading skill & .454 & .136 & .457 & 3.335 & .001 \\
\hline delegation of work for staffs & .402 & .061 & .404 & 6.625 & .105 \\
\hline the way of providing helps for staffs & .199 & .025 & .267 & 8.047 & .057 \\
\hline trust on clerk & .333 & .056 & .358 & 5.984 & .000 \\
\hline friendly with clerk & .446 & .149 & .449 & 2.990 & .003 \\
\hline sense of responsibility & .400 & .063 & .401 & 6.371 & .009 \\
\hline
\end{tabular}

\subsection{Test of Association of Job Satisfaction and Supervisor Performance}

The following table shows the cross tabulation and chisquare test of association of overall job satisfaction and overall supervisor performance at Debre Berhan University. The result reveals that there is a significant association with overall job satisfaction and overall performance of supervisor. This indicates that job satisfaction is highly depends on the overall performance of immediate supervisor. This is in line with the result of Chakrabarty [2]. So in order to enhance the job satisfaction of employees the nomination of supervisor should be merit based.

Table 3. Test of association of job satisfaction and supervisor performance.

\begin{tabular}{lllll}
\hline \multirow{2}{*}{ Variables } & \multicolumn{3}{c}{ Overall performance } & $\begin{array}{l}\text { Pearson chi } \\
\text { square (sig) }\end{array}$ \\
\cline { 2 - 4 } & Categories & Unsatisfied & satisfied & 8.924 \\
Overall Job & unsatisfied & 126 & 46 & $(.000)$ \\
satisfaction & satisfied & 47 & 53 & \\
\hline
\end{tabular}

\section{Conclusions}

Satisfaction of human resource finds close links to highly motivated employees. Motivated employees then develop loyalty or commitment to the organization resulting to greater productivity and lower turnover rates (Frame, 2004).

The main objective of the study is identifying factors affecting employee's job satisfaction and supervisor performance at Debre Berhan University. To meet the objective of the study a sample of 272 employees have taken. Both descriptive and inferential statistics have been used. Logistic regression, multiple linear regression and chi-square test of association are the basic inferential statistics that have used in this study. The descriptive result of the study reveals that about $63.2 \%$ of the total sampled respondents have not satisfied and the rest $36.8 \%$ of them have satisfied with their job condition in the university. Regarding performance of supervisors the result shows that about $63.6 \%$ of the employees have not satisfied and the rest $36.4 \%$ have satisfied with the overall performance of their immediate supervisors.

Logistic regression analysis of job satisfaction shows that payment for overload, the way of promotion, encouragement of research work, accessibility of office, merit based job allocation, recognition for contributions, responding the need of home and facility of working materials have significant effect on employees job satisfaction at 5\% level of significant. From descriptive and logistic regression result of the study it is evident that promotion, encouragement of research, accessibility of office, recognition for contribution and responding the need of home are source of dissatisfaction of employees of the university.

Multiple linear regression analysis of supervisor performance predict that handles employees complaints, does not allow special privilege, available for customers, being respectful, good leading skill, trust on clerk, and sense of responsibility have significant effect on the supervisor performance at 5\% level of significance. Finally from the result of chi- square test of association of overall job satisfaction and overall performance of supervisor, it is evident that there is a strong association between job satisfaction and supervisor performance in the university.

\section{Recommendations}

Even though the university improved some aspects of working condition of the compound like; terms of payment for overload, internet access and transportation service still there are so many issues that have not improved. From consecutive results of the study the following possible endorsements have been forwarded.

Promotion of staffs is the one basic source of dissatisfaction of employees in the university, so the management of the university should improve the way of promotion based on the legislation of the university.

Even if there is potential manpower in the university the encouragement of research and community service is not interested specially with respect to budget, in order to utilize the available manpower in the university there should be motivated encouragement and recognition for researchers so that scientific environment can be created in the compound.

The accessibility of office for staffs is not adequate and there is overcrowded office, it has its own negative influence 
on the regular teaching and innovating of staffs. So the university should build additional blocks to satisfy need of office of the employees.

The staffs of the university are in high need of home. But the activities that have done to respond the need of staffs for home are not substantial. So the university should work hard to satisfy the need of staffs for home.

From the result of the study employees of the university have not satisfied with the performance of their immediate supervisor. So in order to enhance the level of satisfaction of employees and for the successful accomplishment of the university, the allocation of supervisors in different hierarchy should be merit based.

In order to realize the existing working condition of the university, further investigation with respect to turnover of employees should be conducted.

\section{References}

[1] Arnolds, C. A., \& Boshoff, C. (2001). The challenge of motivating top management: A need satisfaction perspective [Electronic version]. Journal of Industrial Psychology, 27(1).

[2] Chakrabarty S, Oubre DT, Brown G (2008). The impact of supervisory adaptive selling and supervisory feedback on salesperson performance. Ind. Mark. Manage., 37: 447-454.

[3] Ellickson. M. C., \& Logsdon, K. (2002). Determinants of job satisfaction of municipal government employees [Electronic version]. Public Personnel Management, 31(3).

[4] Griffin MA, Patterson MG, West MA (2001). Job satisfaction and team work: the role of supervisor support. J. Organ. Behav., 22: 537-550.

[5] Richard F. Gerson, Gerson, Brenda Machosky (Eds) (1993). Measuring Customer Satisfaction: 49 A Guide to Managing Quality Service: Crisp Publications, Inc.

[6] Smith. M. 2007. How to Measure Satisfaction: Satisfaction Measurement and Theory.

[7] Tam, J. (2004). "Customer satisfaction, service quality and perceived value. An integrative

[8] Terrence and Gordon (1996). Determinants of customer satisfaction in retail banking pp. 15

[9] Voltaire, R. (2003). Customer service and satisfaction: We must cultivate our garden, pp. 18

[10] J. D. Politis (2001) The relationship of various Leadership Styles to Knowledge Management. Leadership and Organization Development Journal, 22(8), p. 354-64. 